\title{
CHARACTERISTICS AND ACCURACY OF LARGE AREA COVERING HEIGHT MODELS
}

\author{
K. Jacobsen
}

\begin{abstract}
Institute of Photogrammetry and GeoInformation, Leibniz University Hannover, Germany jacobsen@ipi.uni-hannover.de
\end{abstract}

Commission I, WG I/4

KEY WORDS: DHM, satellite imagery, InSAR, analysis

\begin{abstract}
:
Large area covering height models are dominantly based on optical and synthetic aperture radar (SAR) space imagery. The vertical accuracy of individual object points determined by automatic matching of optical imagery is in the range of 1.0 ground sampling distance (GSD), but this is not identical to the accuracy of the height model. With the exception of long wavelength SAR data, the Pand L-band, all height models are originally digital surface models (DSM) and not the most often requested digital terrain models (DTM) with the height of the bare ground which have to be generated by filtering. In addition height models are influenced by interpolation, reducing the geometric quality. Large area covering height models are analyzed for their accuracy and characteristics, including the effect of details influenced by the method of determination. The absolute accuracy in addition is affected by the quality of geo-reference, which partly is based on the direct sensor orientation, partly based on ground control points (GCP) or indirectly on other existing height models. The most important influence for the resolution of a height model is the point spacing of the DHM, but details also can be lost by not proper data handling. All height models have lower accuracy in steep terrain, the matching of optical images is influenced by the object contrast, while SAR is affected by layover. By this reason gaps in the height models often are filled with other data causing more heterogeneous character.
\end{abstract}

\section{INTRODUCTION}

Digital height models (DHM) are a basic requirement for any geographic information system (GIS). The number of worldwide or nearly worldwide DHM is growing as well as the possibility to generate regional or local height models for any location of the world. The characteristic of DHM is depending upon the geometric accuracy, the morphologic accuracy, homogeneity, reliability and the definition as digital surface model (DSM) with point height on the visible surface or as digital terrain model (DTM) with the points on the bare ground. The geometric accuracy has to be specified as relative or absolute height accuracy and with the location accuracy - the standard deviation in $\mathrm{X}(\mathrm{SX})$ and $\mathrm{Y}$ (SY). Of course the accuracy is not the same depending upon the local characteristic of the terrain, so in any case it is depending upon the terrain inclination, but also depending upon the contrast in the case of the use of optical images or overlay in the case of SAR. The morphologic accuracy is dominated by the point spacing and the relative geometric accuracy. The original reliability depends upon the method of generating the DHM, but it can be improved by automatic and manual post-processing.

\section{SPECIFICATION OF GEOMETRIC ACCURACY}

Accuracy figures traditionally are based on presupposed normal distribution of discrepancies. Such a prerequisite usually cannot be reached for height models. It requires homogenous conditions in the handled area, but the terrain inclination may change in the area causing different accuracy, the contrast or layover may not be the same and most important, the not avoidable influence of (remaining) vegetation and buildings may vary. So the statistical conditions are not corresponding to normal distribution of height discrepancies. The function of the accuracy figures are for estimation of probable discrepancies, so the accuracy figure which allows the best estimation under the condition of usual height models should be used.

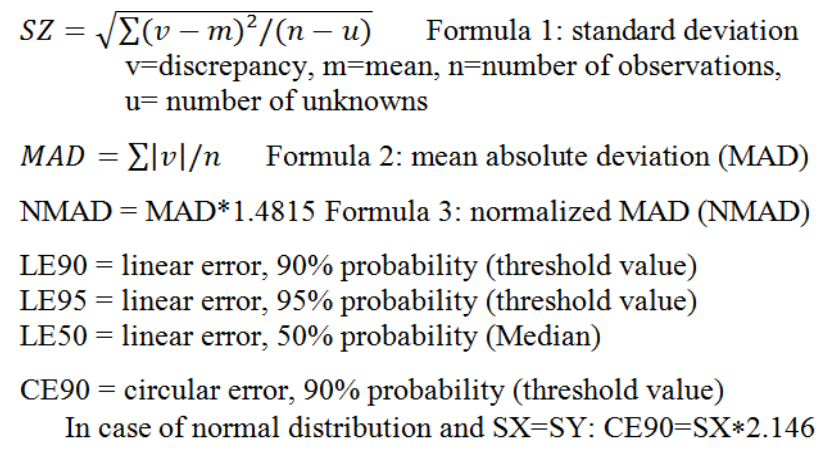

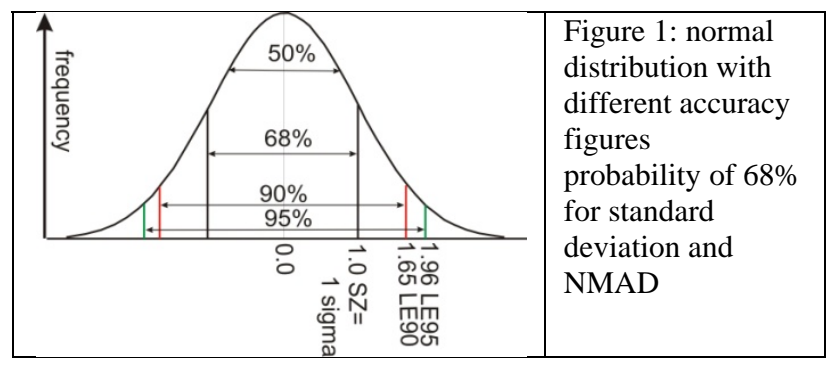

The above listed accuracy figures are in use for different applications. The standard deviation as root mean square value is the classical figure. Instead of this the linear expression MAD, corresponding to $50 \%$ probability, can be used or better the normalized MAD (NMAD) with the same probability of $68 \%$ as the standard deviation. For normal distributed discrepancies NMAD has the same value as the standard deviation. LE90 or LE95 are just threshold values and do not 
represent the whole amount of discrepancies. Corresponding to the Joint Committee for Guides in Metrology, including ISO as a member, (JCGM 100:2008), the accuracy figures or uncertainty parameters are "parameters, associated with the result of a measurement that characterizes the dispersion of the value that could reasonably be attributed to the measurand". JCGM is categorizing the threshold values LE90 and CE90 as "so-called safe uncertainty which cannot be converted to a standard uncertainty without knowledge of how it was calculated" - these threshold values are not recommended.

Before calculation of accuracy figures for height discrepancies, the horizontal fit of the investigated to the reference DHM has to be determined and respected - this should be done by adjustment. Horizontal shifts of height models are common within the range of the horizontal accuracy; they are usually caused by orientation discrepancies or datum problems.



Figure 2: color coded height discrepancies SRTM DSM Pennsylvania against reference DTM, left: whole area, right: only open area without soil degradation

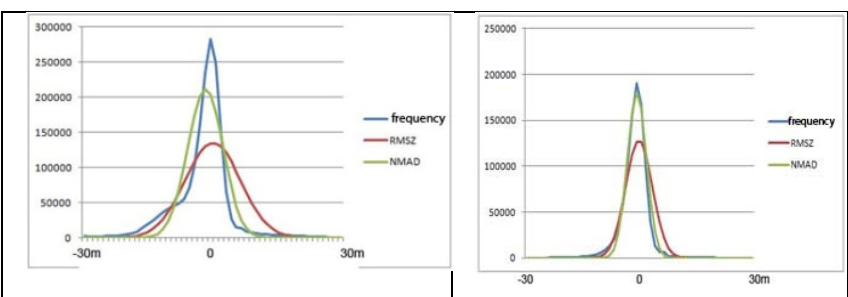

Figure 3: frequency distribution SRTM DSM Pennsylvania against reference DTM, left: whole area, right: only open area

\begin{tabular}{|l|c|c|}
\hline & Whole area & Open area \\
\hline RMSZ & $6.44 \mathrm{~m}$ & $3.55 \mathrm{~m}$ \\
\hline Bias & $1.75 \mathrm{~m}$ & $-0.56 \mathrm{~m}$ \\
\hline SZ & $6.20 \mathrm{~m}$ & $3.51 \mathrm{~m}$ \\
\hline NMAD & $4.11 \mathrm{~m}$ & $2.53 \mathrm{~m}$ \\
\hline SZ F(slope) & $5.90 \mathrm{~m}+21.8 \mathrm{~m} * \tan (\alpha)$ & $2.95 \mathrm{~m}+13.0 \mathrm{~m} * \tan (\alpha)$ \\
\hline NMAD F(slope) & $3.57 \mathrm{~m}+30.6 \mathrm{~m} * \tan (\alpha)$ & $2.06 \mathrm{~m}+14.4 \mathrm{~m} * \tan (\alpha)$ \\
\hline LE90 & $8.18 \mathrm{~m}$ & $5.57 \mathrm{~m}$ \\
\hline Factor LE90 to SZ & & 1.27 \\
\hline LE95 & $12.43 \mathrm{~m}$ & $7.24 \mathrm{~m}$ \\
\hline Factor LE95 to SZ & \multicolumn{2}{|c|}{1.93} \\
\hline
\end{tabular}

Table 1: accuracy figures SRTM DSM Pennsylvania

The example shown in figures 2 and 3 is typical for all height models if a DSM is compared with a reference DTM. In figure 2 on left hand side, indicated by red and blue color, the forest area has large discrepancies which are not included in the investigation of the open area. The frequency distribution (blue line) for the whole area includes the effect of the forest to the differences between SRTM DSM and the reference DTM. By this reason the frequency distribution is not symmetric. The large discrepancies cause enlarged values for the standard deviation, the NMAD and the LE-figures. The normal distribution based on RMSZ (red line) and NMAD (brown line) do not express the frequency distribution. If the investigation is limited to the open area (no forest) without areas with soil degradation, the normal distribution based on the NMAD fits very well with the frequency function, while the normal distribution based on the root mean square differences, which in this case nearly is the same as SZ, is not fitting well (figure 3, right hand side). That means there are a higher number of larger discrepancies included as corresponding to the normal distribution, influencing the square sum more as the linear error NMAD. This is a typical result achieved for nearly all checked height models. NMAD expresses the frequency distribution quite better as the standard deviation, with the exception that more large discrepancies are included. But it is a question of discussion if these large discrepancies shall be respected for the characterization of the height models - the larger discrepancies often are caused by elements not belonging to an open area as single trees or small group of trees and buildings. In addition to such elements the accuracy is not the same depending upon the terrain inclination as table 1 shows with NMAD and SZ as functions of terrain inclination. Depending upon these adjusted functions, the accuracy for flat parts is better as for inclined parts. A horizontal uncertainty has an influence to the height by the horizontal uncertainty multiplied by the tangent of the terrain slope, so the factor depending upon the terrain inclination may express the horizontal accuracy, but for inclined terrain the vertical accuracy is not as good as for horizontal terrain making the relation more complex.

The threshold value LE90 in the case of normal distributed discrepancies should be 1.65 times larger as the standard deviation and for LE95 the factor should be 1.96. For the whole area the factor for LE95 is within the tolerance range, but for LE90 the factor is just 1.27 instead of 1.65. For the correct investigation without areas with forest and soil degradation for LE90 the relation to SZ is not far away from the factor corresponding to the normal distribution. This is an individual result - the threshold values LE90 and LE95 are very sensitive for remaining larger discrepancies and do not express the frequency distribution well, so there is no statistical justification for these threshold values. If by some reasons a tolerance limit has to be used, the tolerance limit should be based on NMAD or SZ together with a percentage of probability, giving some factors for statistical justified accuracy values.

\section{LARGE AREA COVERING HEIGHT MODELS}

\begin{tabular}{|l|c|c|c|}
\hline Height model & Covered area & $\begin{array}{c}\text { Point } \\
\text { spacing }\end{array}$ & source \\
\hline GMTED 2010 & Whole world & $\begin{array}{c}7.5 \\
\text { arcsec }\end{array}$ & $\begin{array}{c}\text { SRTM + } \\
\text { other }\end{array}$ \\
\hline SRTM C-band & $\begin{array}{c}-56^{\circ}+62.25^{\circ} \\
\text { latitude }\end{array}$ & 3 arcsec & InSAR \\
\hline ASTER GDEM2 & $\begin{array}{c}-83^{\circ}+83^{\circ} \\
\text { latitude }\end{array}$ & 1 arcsec & $\begin{array}{c}\text { ASTER } \\
\text { stereo }\end{array}$ \\
\hline $\begin{array}{l}\text { SPOT DEM / } \\
\text { Reference 3D }\end{array}$ & $43 \%$ of land & 1 arcsec & $\begin{array}{c}\text { SPOT 5- } \\
\text { HRS }\end{array}$ \\
\hline Planet Observer & Whole world & 3 arcsec & $\begin{array}{c}\text { SRTM + } \\
\text { other }\end{array}$ \\
\hline $\begin{array}{l}\text { NEXT Map } \\
\text { World 30 }\end{array}$ & Whole world & 1 arcsec & $\begin{array}{c}\text { Fused SRTM + } \\
\text { ASTER + other } \\
\text { in polar area }\end{array}$ \\
\hline NEXT Map & $7 \%$ of land & $5 \mathrm{~m}$ & Aerial InSAR \\
\hline EURO-Maps 3D & On request & $5 \mathrm{~m}$ & Cartosat 1 \\
\hline $\begin{array}{l}\text { TanDEM-X } \\
\text { Global DEM }\end{array}$ & Whole world & $\begin{array}{c}0.4 \\
\text { arcsec }\end{array}$ & $\begin{array}{c}\text { TanDEM-X } \\
\text { InSAR }\end{array}$ \\
\hline
\end{tabular}

Table 2: large area covering height models 
All height models listed in table 2 are originally digital surface models based on optical stereo satellites or InSAR with X- or Cband delivering the height of the visible surface, but very often a DTM is required. If enough points of the bare ground are included in the DSM, a DTM can be generated by filtering the elements not belonging to the bare ground (Passini et al. 2002, Day et al. 2013). In a closed forest without points of the bare ground a filtering has limited effort. In any case a final quality check and the last step of cleaning from DSM to DTM have to be done manually. A quality check of a DSM with point spacing in the range of $5 \mathrm{~m}$ to $30 \mathrm{~m}$, including elimination of obvious blunders and flattening of larger water bodies, will be done by private companies for approximately $3 € / \mathrm{km}^{2}$ up to $5 € / \mathrm{km}^{2}$, a change from DSM to DTM requires approximately $10 € / \mathrm{km}^{2}$. So for example Astrium offers TerraSAR-X height models as DSM Basic (without quality check) for $17 € / \mathrm{km}^{2}$, as DSM for $20 € / \mathrm{km}^{2}$ and as DTM for $30 € / \mathrm{km}^{2}$.

GMTED2010 (https://lta.cr.usgs.gov/GMTED2010) replaced the former GTOPO30. USGS and US NGA generated a new world wide covering product with a point spacing up to 7.5 arcsec (231m at the equator) which is mainly based on SRTM and ASTER GDEM.

The SRTM C-band DSM with data from year 2000 originally is available with 1 arcsec point spacing ( $\sim 31 \mathrm{~m}$ at the equator), but in the WEB, with the exception of the USA, it is distributed only with 3 arcsec point spacing. As typical for SAR the original data have gaps in mountainous areas, cities with large buildings, on water surfaces and dry sand deserts. These gaps have been filled; very often SPOT 5-HRS data have been used. In parallel to the C-band, based on the German-Italian X-band SAR in the Space Shuttle also DSM with 1 arcsec are generated. These DSM are now available free of charge with the original spacing from the German Aerospace Centre DLR, but the Xband DSM has larger gaps between the data strips. The geometric quality of the C-band and the X-band height values are approximately the same (Jacobsen 2010).

The Japanese instrument ASTER on the US platform Terra has with the bands $3 \mathrm{~A}$ and $3 \mathrm{~B}$ a stereoscopic coverage with $15 \mathrm{~m}$ GSD and a height to base relation of 2.1. With all available stereo models the ASTER GDEM, with 1 arcsec spacing, has been generated covering the area from $83^{\circ}$ southern up to $83^{\circ}$ northern latitude. With the version 2 (GDEM2) in 2011 the horizontal location of the individual DSM have been improved, so with the GDEM2 the morphologic quality corresponds to the 1 arcsec spacing - this was not the case for the first version (figure 7).

SPOT DEM, also distributed as Elevation 30, and the improved version Reference 3D are based on SPOT 5-HRS, the additional stereo sensor on SPOT 5 having 5m GSD in flight direction. These height models are available for $43 \%$ of the land surface, especially for Europe up to China, North Africa and other parts. For most of the other areas images are available and height models are generated on request. Reference 3D is improved against SPOT DEM by better orientation and a quality check.

Planet Observer mainly is based on SRTM; it has only limited advantages against the free of charge SRTM DSM.

NEXT Map World30 from Intermap Technologies is a fusion of 3 arcsec SRTM and 1 arcsec ASTER GDEM with improved orientation using ICESat laser profile points.

NEXT Map was created by Intermap Technologies with airborne X-band InSAR from slightly more than $10 \mathrm{~km}$ flying elevation. The point spacing of $5 \mathrm{~m}$ includes quite more details as the preceding named height models.

Euromap, belonging to GAF, generates with Cartosat-1 stereo models DSM by pixel based Semi Global Matching (SGM). The stereo satellite Cartosat 1, launched in 2005, has 2.5m GSD and a height to base relation of 1.6. Dominantly the DSM or refined DTM are made on request. The direct sensor orientation of Cartosat-1 is limited why in areas without GCPs SRTM DHM is used as geometric reference together with block adjustment (d'Angelo, Reinartz 2012).

TanDEM-X is an InSAR-configuration of the German Aerospace Centre DLR which shall finish in 2014 a Global DEM with a point spacing of 0.4 arcsec, corresponding to $12 \mathrm{~m}$ at the equator. Within a private public partnership (ppp) DLR will generate the height models and Astrium will distribute it. In 2014 this will be the worldwide covering height model with the highest resolution and highest accuracy which is also quite homogenous.

In addition to these DHM, height models can be generated on request with existing or to be ordered optical or SAR space images. The theoretical imaging capacity of the very high resolution optical space images, able to generate stereo pairs from the same orbit with $1 \mathrm{~m}$ GSD or better, has been enlarged to more as 5.2 million $\mathrm{km}^{2} /$ day against the imaging capacity of IKONOS and QuickBird of 0.28 million $\mathrm{km}^{2} /$ day by the factor 19. So the waiting time for getting new space imageries has been reduced. Astrium offers with Elevation 4 \& 1 DSM based on Pleiades $1 \mathrm{~A}$ and $1 \mathrm{~B}$ as well as GAF offers height models based on optical stereo or tri-stereo combinations.

Beside the InSAR configuration of TanDEM-X, DSM can be produced by radargrammetry with the $\mathrm{C}$ - respectively X-band SAR-satellite imageries from Radarsat, COSMO-Skymed or RISAT. With ALOS-2, announced for 2013, SAOCOM, starting in 2014 and RISAT-3 in 2016 L-band SAR will be available. L-band is penetrating the vegetation, so directly DTMs can be generated. Only the influence of buildings has to be eliminated to get a clear DTM. The TanDEM-L concept of the DLR would be able to cover the whole world with such a product.

\section{ACCURACY AND CHARACTERISTICS}

\begin{tabular}{|c|c|c|c|c|}
\hline DHM & $\begin{array}{c}\text { SX } \\
\text { SY }\end{array}$ & $\begin{array}{c}\text { SZ } \\
\text { absolute } \\
<20 \%\end{array}$ & $\begin{array}{c}\text { SZ } \\
\text { relative } \\
<20 \%\end{array}$ & remark \\
\hline SRTM & $\begin{array}{c}3.5 \mathrm{~m}- \\
5 \mathrm{~m}\end{array}$ & $6 \mathrm{~m}-8 \mathrm{~m}$ & $4 \mathrm{~m}$ & X-Band \\
\hline $\begin{array}{c}\text { ASTER } \\
\text { GDEM2 }\end{array}$ & $10 \mathrm{~m}$ & $10 \mathrm{~m}$ & $6 \mathrm{~m}$ & $\begin{array}{c}\text { several ASTER } \\
\text { models }\end{array}$ \\
\hline $\begin{array}{c}\text { Elevation 30 } \\
\text { (SPOT DEM) }\end{array}$ & $14 \mathrm{~m}$ & $12 \mathrm{~m}$ & $6 \mathrm{~m}$ & $\begin{array}{c}\text { based on } \\
\text { SPOT 5-HRS }\end{array}$ \\
\hline $\begin{array}{c}\text { Reference } \\
\text { 3D }\end{array}$ & $6 \mathrm{~m}$ & $5 \mathrm{~m}$ & $3 \mathrm{~m}$ & $\begin{array}{c}\text { refined, quality } \\
\text { check }\end{array}$ \\
\hline $\begin{array}{c}\text { NEXTMap } \\
\text { World 30 }\end{array}$ & $3.5 \mathrm{~m}-$ & $5 \mathrm{~m}$ & $4 \mathrm{~m}$ & $\begin{array}{c}\text { dominated by } \\
\text { SRTM }\end{array}$ \\
\hline $\begin{array}{c}\text { NEXTMap } \\
1 \mathrm{~m}\end{array}$ & $\begin{array}{c}0.6 \mathrm{~m}- \\
>1.8 \mathrm{~m}\end{array}$ & $0.6 \mathrm{~m}-$ & $\begin{array}{c}\text { airborne InSAR } \\
\text { X-band }\end{array}$ \\
\hline $\begin{array}{c}\text { EURO- } \\
\text { MAPS 3D }\end{array}$ & $5 \mathrm{~m}$ & $\begin{array}{c}<6 \mathrm{~m} \\
(3 \mathrm{~m})\end{array}$ & $2.5 \mathrm{~m}$ & $\begin{array}{c}\text { Cartosat-1 } \\
2.5 \mathrm{~m} \text { GSD }\end{array}$ \\
\hline $\begin{array}{c}\text { VHR optical } \\
\text { satellites }\end{array}$ & $\begin{array}{c}2 \mathrm{~m} \\
(<1 \mathrm{~m})\end{array}$ & $3 \mathrm{~m}(1 \mathrm{~m})$ & $<1 \mathrm{~m}$ & $\begin{array}{c}\text { for images with } \\
\text { imm GSD }\end{array}$ \\
\hline $\begin{array}{c}\text { TanDEM-X } \\
\text { Global } \\
\text { DEM }\end{array}$ & $<4.7 \mathrm{~m}$ & $\begin{array}{c}<6 \mathrm{~m} \\
(, \text { in range } \\
\text { of meter })\end{array}$ & $1.2 \mathrm{~m}$ & $\begin{array}{c}\text { homogenous, } \\
\text { actual }\end{array}$ \\
\hline
\end{tabular}

Table 3: accuracy overview (standard deviations)

The accuracy figures in table 3 are estimations partially based on own investigations and partially on specifications of the commercial producers - they have been checked as being realistic. They are partially converted from CE90 respectively LE90 to standard deviations using the relation for normal 
distributed discrepancies. So for TanDEM-X Global DEM the original specification for terrain with inclination not exceeding $20 \%$ is $\mathrm{SX}=\mathrm{SY}=4.7 \mathrm{~m}$ and $\mathrm{SZ}_{\text {absolute }}<6 \mathrm{~m}$, but with improved orientation $\mathrm{SZ}_{\text {absolute }}$ now is mentioned as within meter range (Eineder et al. 2013). The relative standard deviation is valid for open areas - if the DSM is compared with a reference DTM, the root mean square differences of course are larger, but this is related to the specification of the heights and not so much to the real accuracy.

Not in any case the reference height models used for the estimation of the DSM are satisfying free of error, making the analysis difficult. So for example a WorldView-2 height model close to Istanbul was compared against an overlapping, independent WorldView-2 DSM, a DTM from the survey administration (Büyüksalih et al 2012) and later against a laser scanning DTM (table 4).

\begin{tabular}{|l|c|c|}
\hline & SZ & NMAD \\
\hline $\begin{array}{l}\text { WV-2 DSM against } \\
\text { WV-2 DSM, open area }\end{array}$ & $0.86 \mathrm{~m}$ & $0.69 \mathrm{~m}$ \\
$0.66 \mathrm{~m}+1.79 * \tan \alpha$ & $0.50 \mathrm{~m}+1.29 * \tan \alpha$ \\
\hline $\begin{array}{l}\text { WV-2 DSM against } \\
\text { reference DTM }\end{array}$ & $3.65 \mathrm{~m}$ & $2.23 \mathrm{~m}$ \\
\hline $\begin{array}{l}\text { WV2 DSM against } \\
\text { reference, open area }\end{array}$ & $2.21 \mathrm{~m}$ & $1.72 \mathrm{~m}$ \\
\hline $\begin{array}{l}\text { WV-2 DSM against } \\
\text { laser, open area }\end{array}$ & $1.05 \mathrm{~m}$ & $\begin{array}{c}0.71 \mathrm{~m} \\
0.83 \mathrm{~m}+2.28 * \tan \alpha\end{array}$ \\
\hline
\end{tabular}

Table 4: accuracy analysis of WorldView-2 DSM Istanbul

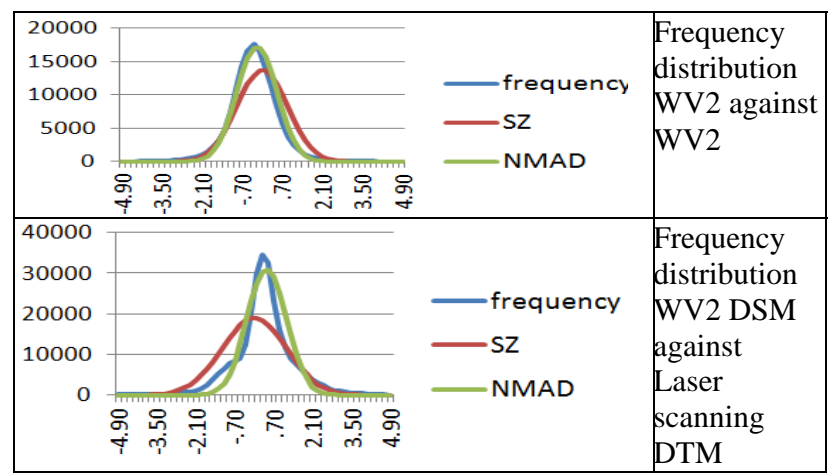

Figure 4: frequency distribution with overlaid normal distribution based on RMSZ and NMAD

It is obvious, that the reference DTM from the survey administration has a lower accuracy as the WorldView-2 DSM. This is not the case for the laser scanning DTM. The discrepancies between the WorldView-2 DSM and the laser scan DTM are slightly larger as the discrepancies between both independent WorldView-2 DSMs. This is caused by vegetation in the open area, shown also by the not symmetric part of the frequency distribution in figure 4 , below. As usual SZ is slightly larger as NMAD caused by larger discrepancies more often available as under the condition of normal distribution. As for all investigated height models, the normal distribution based on NMAD expresses the frequency distribution better as the normal distribution based on SZ. For all analyzed DHMs the discrepancies between the used DHM and the reference DHM can be expressed very good with the function $\mathrm{SZ}=\mathrm{A}+$ $\mathrm{B} * \tan ($ terrain inclination). That means the accuracy for horizontal terrain corresponds to factor A.

Well determined object points can be determined with a relative standard deviation of approximately 1.0 GSD, the amount exceeding this can be explained by the object definition. Because of this, the results can be improved by filtering the
DSM for objects not belonging to the bare ground (Passini et al. 2002, Day et al. 2013) (table 5, figure 5).

The results of all height models determined by matching optical stereo pairs are similar, the accuracy depends linear upon the GSD, the height to base relation has only a limited influence while with a small angle of convergence the images are more similar, improving the matching, and with a larger angle of convergence the geometry compensates the not so good matching. Area based matching uses the hypothesis of steady and differentiable ground. If this is not the case, as for buildings and rocky areas, the matching is smoothing the object. This can be solved by pixel based matching as Semi Global Matching (SGM) (Alobeid et al. 2011), giving the correct building shape.

\begin{tabular}{|l|c|c|}
\hline Test area Warsaw & SZ & NMAD \\
\hline Cartosat-1 DSM & $3.83 \mathrm{~m}$ & $2.64 \mathrm{~m}$ \\
\hline Cartosat-1 filtered & $2.58 \mathrm{~m}$ & $2.30 \mathrm{~m}$ \\
\hline Cartosat-1 open + filtered & $2.51 \mathrm{~m}$ & $2.27 \mathrm{~m}$ \\
\hline
\end{tabular}

Table 5: accuracy analysis of a Cartosat- 1 height model

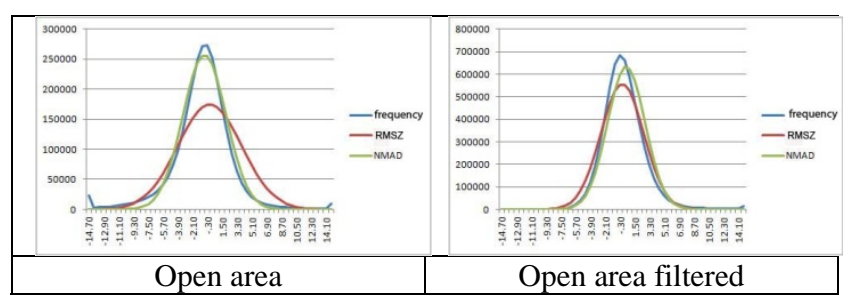

Figure 5: Frequency distribution of Cartosat-1 DSM in Warsaw test area

The results achieved with Cartosat- 1 stereo pair in the Warsaw test area confirms as other data the relations explained at the example of WorldView-2. The system accuracy is in the range of 1.0 GSD. The standard deviation is sensitive for larger discrepancies, so SZ exceeds NMAD, but after filtering the number of larger discrepancies is reduced, so the difference between SZ and NMAD becomes smaller and the normal distribution based on SZ is more similar to the normal distribution based on NMAD and the real frequency distribution.



Figure 6: Root mean square discrepancies of SRTM, ASTER GDEM and ASTER GDEM2, originally, after horizontal adjustment, after horizontal adjustment for flat area 
In figure 6 the analysis of SRTM DSM, ASTER GDEM and GDEM2 in 9 test areas is shown. The SRTM DSM has a standard deviation SX and SY in the range of $3.5 \mathrm{~m}$ up to $5 \mathrm{~m}$, while for ASTER GDEM2 it is in the range of $10 \mathrm{~m}$. For the first version ASTER GDEM it was slightly below. The horizontal shifts have been determined by adjustment, improving the RMSZ after respecting this. By this improvement the results of the test areas became more similar. If the accuracy is computed only for the flat parts (figure 6 below), with the exception of ASTER for the Warsaw test area, the results are more homogenous. For ASTER GDEM and GDEM2 in the Warsaw test area only between 1 and 8 stereo models ( 2 up to 16 stacks) have been used, this is quite less as for the other test areas where in the average up to 25 stereo models were respected. . In the average for ASTER GDEM2 SZ as a function of the number of images per object point can be estimated with:

$\mathrm{SZ}=12.0 \mathrm{~m}-0.08 *($ images/objet point $) \quad$ formula $4:$ Dependency of SZ for ASTER GDEM2

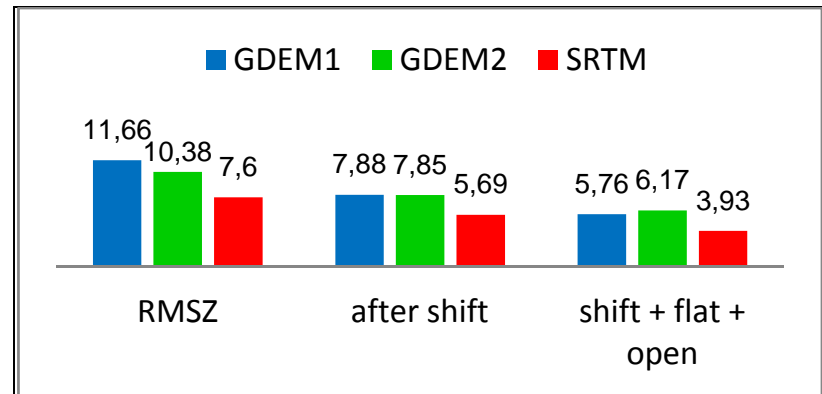

Figure 6: root mean square RMSZ for 12 test areas

Figure 6 demonstrates that the orientation accuracy of the ASTER DSM for ASTER GDEM is not as good as for GDEM2 - after shifting GDEM it has a similar accuracy as GDEM2. The strong dependency upon the terrain inclination is obvious. In any case SRTM has a better accuracy as GDEM or GDEM2. The dependency upon shift and for flat and open areas exists for all height models and not just for SRTM and ASTER

For ASTER GDEM the individual stereo models have not been improved by horizontal fit of the scenes together, the heights have just been averaged. By this reason the morphologic information was reduced and corresponded to approximately 3 arcsec point spacing - not better as SRTM with 3 arcsec point spacing. This was improved by ASTER GDEM2, where the morphologic information has the full details of 1 arcsec point spacing (figure 7).

The original gaps of SRTM caused by layover, dry sand deserts and water surfaces have been filled with other data - often SPOT DEM has been used (Reuter et al. 2007). Reverse the gaps of Elevation 30 / Reference 3D, especial in forest areas without satisfying contrast, have been filled with SRTMheights. This causes some inhomogeneous parts, but they are mentioned in the quality layer of Elevation 30 / Reference 3D. Which of the shown accuracy figure is important depends upon the application. The results after shifting are the relative accuracy, important for morphologic information, while the original RMSZ may be important for flight control. The accuracy after shifting for flat and open areas may be important for agriculture purposes or for city planning.

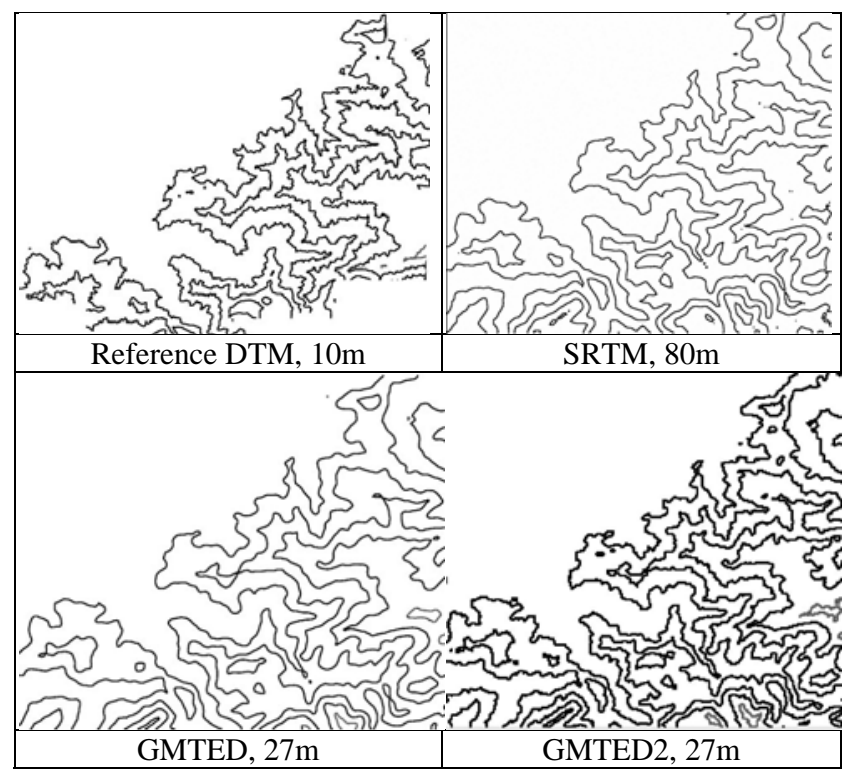

Figure 7: Contour lines based on different height models, with point spacing corresponding to actual latitude

\section{ADVANTAGE AND DISADVANTAGE OF THE HEIGHT MODELS}

\begin{tabular}{|c|c|c|}
\hline DHM & advantage & disadvantage \\
\hline GMTED 2010 & $\begin{array}{c}\text { Free of charge, also } \\
\text { polar region }\end{array}$ & $\begin{array}{l}\text { Not homogenous, } \\
\text { spacing } 7.5 \text { arcsec }\end{array}$ \\
\hline SRTM & $\begin{array}{l}\text { Free of charge, } \\
\text { relatively accurate }\end{array}$ & $\begin{array}{l}\text { Spacing 3arcsec, gap } \\
\text { filling in mountains, } \\
\text { cities, sand deserts }\end{array}$ \\
\hline Aster GDEM2 & $\begin{array}{l}\text { Free of charge, } \\
\text { relatively detailed }\end{array}$ & $\begin{array}{l}\text { Not homogenous, not } \\
\text { as accurate as SRTM }\end{array}$ \\
\hline $\begin{array}{c}\text { Elevation } 30 \\
(\text { SPOT DEM) }\end{array}$ & $\begin{array}{l}\text { Homogenous } \\
\text { accuracy }\end{array}$ & $\begin{array}{l}\text { 43\% of land surface, } \\
\text { limited advantage agains } \\
\text { SRTM, problems in } \\
\text { forest areas }\end{array}$ \\
\hline Reference 3D & $\begin{array}{c}\text { Homogenous } \\
\text { accuracy, better as } \\
\text { Elevation } 30\end{array}$ & $\begin{array}{l}\text { 43\% of land surface, } \\
\text { limited advantage } \\
\text { against SRTM, } \\
\text { problems in forest }\end{array}$ \\
\hline $\begin{array}{c}\text { NEXTMap } \\
\text { World } 30\end{array}$ & $\begin{array}{c}\text { Improved orientation } \\
\text { of SRTM }\end{array}$ & $\begin{array}{l}1 \text { arcsec spacing, not } \\
\text { free of charge }\end{array}$ \\
\hline NEXTMap & $\begin{array}{l}\text { High resolution of } \\
5 \mathrm{~m} \text {, in open areas } \\
\text { high accuracy }\end{array}$ & $\begin{array}{c}\text { Not homogenous } \\
\text { accuracy, expensive }\end{array}$ \\
\hline $\begin{array}{c}\text { EURO-MAPS } \\
\text { 3D }\end{array}$ & $\begin{array}{l}\text { High resolution of } \\
5 \mathrm{~m}, \mathrm{SZ}_{\text {relative }}=2,5 \mathrm{~m}\end{array}$ & $\begin{array}{l}\text { In most areas not } \\
\text { existing, has to be } \\
\text { generated }\end{array}$ \\
\hline $\begin{array}{c}\text { VHR } \\
\text { optical } \\
\text { satellites }\end{array}$ & $\begin{array}{l}\text { Very high resolution, } \\
\mathrm{SZ} \text { relative }<1 \mathrm{~m}, \\
\text { regional best object } \\
\text { information }\end{array}$ & $\begin{array}{l}\text { DHM have to be } \\
\text { generated, very } \\
\text { expensive, only } \\
\text { regional and local }\end{array}$ \\
\hline $\begin{array}{c}\text { TanDEM-X } \\
\text { Global DEM }\end{array}$ & $\begin{array}{c}\text { Homogenous } \\
\text { accuracy, relative } \\
\text { actual, no waiting } \\
\text { time, } \mathrm{SZ}_{\text {relative }}=1.2 \mathrm{~m} \text {, } \\
\text { for large areas } \\
\text { unrivaled }\end{array}$ & $\begin{array}{c}\text { Expensive, } \\
\text { Basic DSM available } \\
2014\end{array}$ \\
\hline
\end{tabular}

Table 6: advantages, disadvantages of DHM

The mentioned height models including height models from VHR optical images and SAR-satellites cannot be compared directly. Of course the free of charge versions GMTED 2010, 
SRTM and ASTER GDEM2 have another function as the commercial once. Nevertheless some important characteristics may cause the decision for the use of the different versions.

Elevation $30 /$ Reference 3D are covering only $43 \%$ of the whole land area, for most of the other parts SPOT 5-HRS stereo pairs are available, so on request the height models can be generated.

The airborne InSAR height model NEXTMap of Intermap Technologies is very detailed with $5 \mathrm{~m}$ spacing. The geometric quality depends upon the area - the highest accuracy is available for open areas, a lower accuracy for mountains, build up area and forest. DTM is available as post processing option. It is limited to West Europe, the USA, parts of Indonesia and Australia. Additional areas cannot just be ordered; in addition a flight allowance is required.

EURO-MAPS 3D as well as Elevation 1 \& 4 and height models based on VHR satellite images have to be generated after order, so a waiting time exist.

With TanDEM-X Global DEM a worldwide DSM will be available in 2014 having 0.4 arcsec $(\sim 12 \mathrm{~m})$ spacing and a relative accuracy of $\mathrm{SZ}=1.2 \mathrm{~m}$ for sub-areas of $1^{\circ} \times 1^{\circ}$. The homogenous quality of this DSM only can be reached with VHR satellite stereo pairs and aerial InSAR. This DSM will not be available free of charge, so the use will be an economical question.

\section{CONCLUSION}

The geometric accuracy of height models is complex. We have to separate between relative and absolute vertical accuracy, in addition horizontal displacements have to be respected. In addition the accuracy depends upon the terrain inclination, terrain roughness and contrast.

Scene orientation can be based on direct sensor orientation or on ground control points. Without GCPs there will be a difference between absolute and relative orientation. By block adjustment using control information from ICESat points and shoreline information, the height orientation can be improved up to a level close to GCPs. Scenes with lower horizontal accuracy can be fitted to the SRTM DEM having absolute location accuracy in the range of $3.5 \mathrm{~m}$ up to $5 \mathrm{~m}$.

For image matching there is a trend from area based matching to pixel based matching by SGM or corresponding methods with advantages in build up areas and mountains.

With the exception of P- and L-band SAR all height models are DSM. By filtering and manual editing during post-processing DTM can be generated with some limitations and slightly reduced morphologic details. The vegetation is changing the height faster as the terrain by erosion, gravel pits and quarries, so for DSM the actual height information may be more important as for DTM.

The linear NMAD as accuracy figure expresses the frequency distribution of the height discrepancies against a reference DHM better as the standard deviation, based on the square sum of the discrepancies, so it should be preferred for estimation of the dispersion of the height values. The higher amount of larger discrepancies as corresponding to the normal distribution may be explained by remaining effects of vegetation and buildings if a DSM in the open areas is compared with a DTM. After filtering the difference between NMAD and SZ is limited.

For worldwide covering DHM InSAR configurations as SRTM and TanDEM-X have the advantage of higher capacity. The announced relative standard deviation of $1.2 \mathrm{~m}$ for TanDEM-X Global DEM only can be reached or surpassed by VHR optical satellite stereo pairs, but with the optical images only local or regional DHM can be generated.
Height models should be filtered for elements which should not be included. For DSM this is limited to blunders, blunders cannot be avoided totally, so in any case a quality check, including manual analysis is recommended to guarantee the reliability.

\section{REFERENCES}

Alobeid, A., Jacobsen, K., Heipke, C., Alrajhi, M., 2011: Building Monitoring with Differential DSMs, ISPRS Hannover Workshop 2011, IntArchPhRS Vol XXXVIII-4/W19

Baudoin, A., Schroeder, M., Valorge, C., Bernard, M., Rudowski, V., 2004: A scientific assessment of the High Resolution Stereoscopic instrument on board of SPOT 5 by ISPRS investigators, ISPRS Congress, Istanbul 2004, Int. Archive of the ISPRS, Vol XXXV, B1, Com1, pp 372-378, http://www.isprs.org/publications/archives.aspx

Büyüksalih, G., Baz, I., Alkan, M., Jacobsen, K., 2012: DEM Generation with WorldView-2 Images, ISPRS Symposium Melbourne 2012, IntArchPhRS Vol XXXVIII-B1

Danielson, J., Gesch, D., 2011: Global Multi-resolution Terrain Elevation Data 2010 (GMTED2010),

http://pubs.usgs.gov/of/2011/1073/pdf/of2011-1073.pdf

d'Angelo, P., Reinartz, P., 2011: DSM based orientation of Large Stereo Satellite Image Blocks, Int. Archive of the ISPRS, Vol XXXIX-B1

Day, D., Jacobsen, K., Passini, R., Quillen, S., 2013: A Study on Accuracy and Fidelity of Terrain Reconstruction after Filtering DSMs produced by Aerial Images and Airborne LiDAR Surveys, ASPRS Annual Convention Baltimore 2013

Eineder, M., Bamler, R., Cong, X., Gernhardt, S., Fritz, T., Zhu, X., Balss, U., Breit, H., Adam, N., Floricioiu, D., 2013: Globale Kartierung und lokale Deformationsmessungen mit den Satelliten TerraSAR-X und TanDEM-X, Zeitschrift für Vermessungswesen 1/2013, pp75-94

Jacobsen, K., 2010: Comparison of ASTER GDEMs with SRTM Height Models, EARSeL symposium 2010, Paris, pp 521-526,

http://www.earsel.org/?target=publications/proceedings/sympos ium-2010

JCGM 100:2008 : Evaluation of measurement data - Guide to the expression of uncertainty in measurement,

http://www.bipm.org/utils/common/documents/jcgm/JCGM_10 0_2008_E.pdf

Passini, R., Betzner, D., Jacobsen, K., 2002: Filtering of Digital Elevation Models, ASPRS annual convention, Washington 2002

Reuter, H.I., Nelson, A., Jarvis A., 2007: An evaluation of void filling interpolation methods for SRTM data, International Journal of Geographic Information Science, 21:9, 983-1008 + http://srtm.jrc.ec.europa.eu/literature/Reuteretal2007.pdf

All WEB addresses from April 2013 